Pediatric PulmonologyVolume 52, Issue 9, September 2017, Pages 1119-1120

\title{
Mortality predictive scores for community-acquired pneumonia in children(Letter)
}

- Fernández-Mormontoy, J.,

- Estremadoyro-Gallardo, A.,

- Vargas, O.F.

- Escuela de Medicina, Universidad Peruana de Ciencias Aplicadas, Lima, Perú, Peru

Abstract_View references (5)

[No abstract available]

- ISSN: 87556863

- CODEN: PEPUE

- Source Type: Journal

- Original language: English

- DOI: 10.1002/ppul.23706

- Document Type: Letter

- Publisher: John Wiley and Sons Inc. 